by the presence of the bacillus coli; the patients were suffering from bacilluria and pyuria. They had all suffered from so-called "influenza," one two months previously, another one year, and the third case a few years previously, but in no instance were they known to have contracted typhoid fever. In two of the cases definite urinary symptoms had occurred soon after the attack of "influenza," which in each instance had been severe. No precaution had been taken previously to the isolation of the bacilli, and no case of infection had occurred as far as is known. In two instances the patients were treated with a vaccine prepared from their own organisms, with the result that the paratyphoid bacilli soon disappeared from the urine, although the colon bacilli persisted. In the third example the urine, which only gave a growth of the bacillus paratyphosus A., cleared up under the influence of urotropin and other urinary antiseptics. Although there was no absolute proof, it seems to me very probable that the disease which had been diagnosed as "influenza" was due to infection with the paratyphoid bacilli. The fact that urinary symptoms did not immediately follow the acute illness may be disregarded, because, as previously stated in the case of bacillus coli infections of the urinary tract, it is a matter of common knowledge that urinary infection is often present without the patient being aware of it.

The latent persistence of the typhoid-paratyphoid group of organisms in the tissues is of considerable importance from whatever aspeci, this subject is considered. That organisms which are known to be capable of giving rise to serious epidemics may practically live as saprophytes in our tissues, with or without occasional periods of activity, or be discharged from our bodies and thus be the source of acute infection in a fresh host, must be regarded as a reason for reconsidering our views concerning these infections, and the credit of this is greatly due to the School of Hygiene at Strassburg.

In conclusion, I must apologise for the numerous omissions in this account of the life of certain bacteria in our tissues. The whole subject is surrounded by difficulties which concern almost every detail in pathology and bacteriology. I have endeavoured to point out certain facts relating to bacteria living and multiplying in our tissues in contradistinction to the growth of these organisms outside the body.

\section{FURTHER NOTES ON THE TREATMENT OF SYPHILIS BY ARYLARSONATES.}

\section{By F. J. LAMBKIN, L.R.C.P. \& S. IREL., COLONEI, R.A.M.C.}

IN a paper which $I$ read at the annual meeting of the British Medical Association at Sheffield in August last I recorded 74 cases of syphilis treated by arylarsonates at the Military Hospital, Rochester Row, between August, 1907, and July 1st, 1908, and I have now to chronicle a series of 34 further cases dealt with in a similar manner between July 1st and Oct. 1st, 1908, of which the following are the notes of some of the most interesting.

CASE 1.-Private —- Irish Guards, was admitted on July 7th with an indurated phagedænic sore on the glans penis, profuse macular eruption on the body, inguinal and cervical glandular enlargements, nocturnal headaches, and anæmia with loss of body weight. Treatment consisted of 10 grains of soamin given intramuscularly on alternate days until he had received a total of 100 grains. He was discharged to duty on the 26th, all active signs of the disease having cleared up and the general health much improved; he had gained 6 pounds in weight whilst in hospital.

CASE 2.-Private -C, Coldstream Guards, was discharged from the Royal Herbert Hospital, Woolwich, on June 1st; he had been then under treatment for a "hard chancre," receiving 36 inunctions of mercury. He was admitted to Rochester Row on July 8th with an indurated sore on the penis, inguinal, cervical, and mastoid deep glandular enlargements, mucous patches on the tongue and mouth, and a roseolar rash on the body. His weight was 10 stones 7 pounds. He had the usual soamin course, receiving in all 100 grains by intramuscular injection. All active symptoms had disappeared by the 28 th when he was discharged from hospital. His weight on discharge was 11 stones 1 pound.

CASE 3. - Sergeant --_, R.A.M.C. This was an old case of some months' standing. He had had only an irregular course of treatment, owing to having concealed his disease. He was admitted to Rochester Row on July 8th with severe ulceration of the inside of the cheeks, tongue, and throat, also orchitis of the left testicle. He was put on soamin at once and completed the usual course of 100 grains, at the end of which all ulceration had healed, the size of the testicle was decidedly smaller, and his general health had markedly improved. He had gained 5 pounds in weight whilst in hospital, from which he was discharged on the 25th. This case was remarkable from the fact that although no local applications were made to the ulcerations in the mouth and throat, they healed in a most remarkable manner under the soamin alone.

CASE 4. - Private - - Scots Guards, was discharged from the Royal Herbert Hospital, Woolwich, on May 21st; he had been there under treatment 52 days for " soft chancre." No mercury was given. He was admitted to Rochester Row on July 7th with an indurated scar on the penis, the deep glands in the groins, back of the neck, and mastoid shotted, and a maculo-papular eruption scattered over the body and extremities; he suffered from nocturnal headaches, anæmia, and debility, and was much run down. He had albuminuria. He went through the usual course of soamin, under which all symptoms cleared up, the albumin disappeared, and his. general health improved in a remarkable way. He was discharged to duty on July 29 th. The albumin in this case, as was thought, was due to syphilis which was proved to be: correct by the way it cleared up under treatment.

CASE 5. - Private - Coldstream Guards, was admitted on July 4th with a well-marked "Hunterian chancre on glans penis"; the deep glands in the groin and neck were enlarged. He had the full course of soamin. The induration disappeared and he was discharged on July 25th, and up to date has had no further development of the disease.

CASE 6.-Driver-, A.S.C., was admitted on July 7th with a typical hard chancre at the root of the penis. There were no glandular swellings. He went through the full course of soamin. The induration disappeared and he was discharged to duty on the 23rd. Up to date he is quite free from any further developments.

CASE 7.-Private - , 2nd Grenadier Guards, was. admitted on July 30th with a hard phagedænic-looking chancre on the corona glans, enlarged and shotty deep inguinal and cervical glands, a roseolar rash on the body, nocturnal headaches, anæmia, and general debility. He had the full course of soamin, under which all active signs of the disease gave way, and he was discharged to duty on Sept. 3rd, having much improved in general health. $\mathrm{He}$ had gained 7 pounds whilst under treatment.

CASE 8. - Sergeant —- South Lancashire Regiment, was transferred to Rochester Row from another hospital where he had been under treatment for "lupus." The trouble first showed itself in India in 1905, and consisted of at first a more or less superficial ulceration on, and in the vicinity of, the nose. In hospital this was diagnosed as "lupus," and it appears at first to have healed up under local treatment; however, he had many recurrences of the ulceration which eventually necessitated his being invalided home. In England the same state of affairs went on and he spent most of his time in hospital. He had no specific history and had had no specific treatment; the latter consisted of arsenic internally, local applications, scraping, and $x$ ray exposures. At two different hospitals the tubercle bacillus was detected in smears from the nasal ulceration. On admission at Rochester Row on August 5th he was much run down in general condition, cachectic, and anæmic. The alæ of the nose had been destroyed by ulceration which was still proceeding and spreading to the upper lip. There was a deep serpiginous-looking ulcer at the top of the pharynx, and the soft palate had been almost entirely destroyed by previous ulceration. Smears from the ulceration were negative. The case looked decidedly suspicious of syphilis and it was decided to deal with it as such. Accordingly the patient was put on soamin injections, and on August 12th the following note was entered: "Has had four injections of soamin ( $40 \mathrm{grs}$ ) and the ulceration both of the throat and nose has practically healed." This patient was discharged to his duty on August 30th, having had the usual full course of soamin, 
his condition on discharge being that all ulcers had healed and the state of his general health had improved in a marvellous way (he had gained 8 pounds)

The rapid progress which was made in this case was extraordinary, more especially the way in which the ulcers healed without any local treatment. My reasons for considering this to be probably a specific case was the character of the throat ulceration, age of patient, \&c.

CASE 9.-Private - Irish Guards, was admitted on August 8th with indurated sore on penis, enlarged inguinal and cervical glands, and maculo-papular eruption scattered over the trunk. He went through the usual course of soamin and was discharged to duty on the 31st, all active signs having disappeared. His general health had much improved (he had gained 5 pounds in weight).

CASE 10.-Private —- Grenadier Guards, was discharged from the Royal Herbert Hospital, Woolwich, on June 26th, where he had been then under treatment for 30 days for syphilis and had received 25 inunctions of mercury. He was admitted to Rochester Row on August 10th with indurated scar on the penis, mucous patches on the inside of the cheeks and tongue, and ulceration of the throat, and he was covered with a bright roseolar rash. He went through the course of soamin (100 grains) and was discharged from hospital on Sept. 6th. After having had four injections all ulcers in the mouth had healed and on completing the full course his general health had much improved (he had gained 5 pounds in weight). This case was notable from the rapid manner in which the patches and ulcers healed without any local assistance.

CASE 11.-Lance-Corporal —- A.S.C., was placed on the syphilis register at Woolwich on Feb. 17th, and was stated to have been suffering from a scar on the penis, shotty glands in the groin and neck, and roseolar rash on the body. He had received 19 mercurial inunctions and 12 mercurial injections of one of the soluble salts. He was admitted to Rochester Row on August 11th with condylomata and mucous patches on the penis, scrotum, and tongue. He was put on the course of soamin, which he completed and was discharged on Oct. 1st, all symptoms having disappeared. His health had much improved (he had gained 6 pounds in weight).

Case 12. - Private

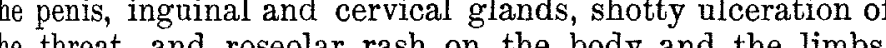
He completed a course of soamin and was discharged on Sept. 14th. The sore had quite healed, the induration had disappeared, as had also the rash and the other symptoms, and the general health was much improved.

CASE 13.-Private —-, Irish Guards, was admitted on August 27th. This was a neglected case. There was a sore under the prepuce and phimosis was present, necessitating circumcision, as well as a well-marked papular eruption over the trunk, the legs, and the arms. The deep inguinal and cervical glands were enlarged, and there was vlceration of the throat. A full course of soamin was completed, and when the patient was discharged from hospital all active symptoms had disappeared and his general health was excellent

CASE 14. - Private —, Scots Guards, was transferred to Rochester Row from another hospital where he was reported to have been doing badly. His condition on admission was generally bad; he was much debilitated and run down. The deep inguinal and cervical glands were enlarged and shotty; the inside of the cheeks, the tongue, and the throat were badly ulcerated; and there was a papulo-pustular eruption on the back and the flanks. The patient has completed a full course of soamin and has done remarkably well. All the ulcers healed rapidly and the rash has practically disappeared.

CASE 15.-The patient, aged 55 years, contracted disease 25 years ago when he had all the classical signs of the disease in its primary and secondary stages. He went through various spasmodic courses of specific treatment at various periods but never had a thorough course. For many years he was quite free from any symptoms until five years ago, when his tongue became sore and leucoplakia formed on it; at the same time an ulcer appeared in the middle of the lower lip; both these lesions have resisted all treatment, including mercury and iodide of potassium internally over long periods. The patient came under my notice on
August 31st. The tongue was furrowed from old ulceration and was marked with leucoplakia, which was well raised in places; there was an ulcer on the lower lip scabbed over; this had been present for the past five years and had been diagnosed as epithelioma on more than one occasion. There was no enlargement of the lymphatics in the neighbourhood. The patient was put on soamin injections, of which he had a full course. After the sixth injection (60 grains) I noted : " Ulcer on lip looking decidedly healthier, general health much improved." After the tenth injection: "Ulcer almost entirely healed, tongue improved, mucous membrane of mouth in much better condition." Further treatment for the present was stopped. The rapid improvement was certainly a surprise and the way in which this old-standing case responded to the arylarsonates was remarkable. After the eighth injection the patient showed signs of toxic effects-i.e., noises in the head and a slight attack of colic; these passed off and he completed his course-in fact, he had a total of 110 grains.

CASE 16. - The patient, aged 54 years, contracted syphilis 30 years ago, when he went through three courses of treatment at Aix-la-Chapelle in two years. There was no further return of the disease until two years ago, when after a severe attack of influenza his tongue became very sore and eventually it ulcerated, leucoplakia also appearing on it. At first the condition was diagnosed as cancer, but eventually syphilis was substituted for the latter and he was treated accordingly. I saw him first on August 25th. The tongue was much thickened and ulcerated both on the dorsum and at the sides, and it was covered with leu oplakia; the inside of the cheeks also was thickened and ulcerated. The gums were in a dreadful state of ulceration the result of excess of mercury. The patient had actually been taking a mixture containing solution of perchloride of mercury and iodide of potassium three times a day for eight months continuously before coming to me. He complained of cramps, especially at night time, in the calves of both legs, and also "pins and needles" in the feet and the toes. Ankle clonus was normal. The patellar reflex was diminished in the right leg and normal in the left. The pupils were normal, the general health much below par, and there was loss of sleep and of appetite. The patient went through a full course of soamin (100 grains), at the end of which the tongue and the mucous membrane of the mouth had much improved, whilst the general health had remarkably done so. Appetite and sleep returned. After the eighth injection the patient complained of noises in the head and a peculiar feeling in both legs.

Notes on Cases Treated with Arsacetin.

CASE 17.-Private — was admitted to hospital on Sept. 25th. On admission he had two small, hard, roundish lumps under the skin of the prepuce; there was no ulceration, and he said that the skin had never been broken, but that was doubtful. He stated that he had had the lumps for the last six months and that he noticed a rash upon him three days before admission. The rash was roseolar in type and was most marked on the chest and the abdomen. The inguinal glands were not enlarged, but those in the neck were hard and shotty. The throat was a little congested. The patient's weight on admission was 12 stones 7 pounds. Oct. 7th: The patient had had four injections of arsacetin (28 grains). The rash was fading and in some places had quite disappeared. The throat was much better and the two small indurated lumps in the prepuce were softer. The patient's weight was 12 stones 12 pounds-a gain of 5 pounds. Oct. 14th: The rash had quite disappeared, the throat was better. Weight 12 stones 13 pounds. Oct. 21st : The patient had had 70 grains of arsacetin. All active symptoms had disappeared and he was apparently in excellent health and was accordingly discharged to duty.

CASE 18.-Private - Irish Guards. Admitted to hospital on Sept. 30th with a well-marked papular eruption all over the body, the chest, the abdomen, the arms, and the legs. The papules were large and some were lenticular and well raised and a few were scaly. The scalp was more or less covered with a papular, and in some places a pustular, eruption and there were some pustules at the junction of the nose and forehead and some on the lower lip. The patient was in hospital on August 22nd with a small hard suspicious sore on the frænum and he left the hospital on Sept. 1st. The hair was falling out and the patient complained of severe frontal headache at night time. 
Both inguinal and cervical glands were enlarged and there were condylomata. Weight on admission, 11 stones 10 pounds. Oct. 7th: The patients had had three injections of arsacetin (21 grains). The rash showed undoubted signs of improvement, the papules were smaller and less bright in colour, and there was a very marked general improvement. He looked much better, the headache had gone, and the pustules on the scalp were drying up. Oct. 14th: The patient had had seven injections (49 grains). The improvement was most marked, the rash had almost disappeared, the scalp was quite normal, and all signs of condyloma had gone. Oct. 21 st : 70 grains of arsacetin had been injected. All symptoms had subsided and the patient's general health and appearance had improved out of all recognition and he was discharged to duty. One could hardly have looked for such a rapid recovery in a case which on admission threatened to be a very severe one and I have seldom seen a better result.

CASE 19.-Private - - Irish Guards, was admitted to hospital on August 28th. He then had a large ulcerating sore involving the frænum, the glans, and part of the prepuce. The base of the ulcer was indurated. He also had a bright red roseolar eruption on the chest, the abdomen, and the back, and a few scattered papules. There was a large indurated gland in the left groin. The patient's weight was 12 stones. Oct. 7th : The patient had had four injections of arsacetin (28 grains). The rash showed signs of fading and the patient looked better. The sore had healed. Weight, 12 stones 3 pounds. Oct. 14th : The patient had had seven injections ( 49 grains). There was a very marked improvement, the rash had quite disappeared in some places, and where it was still present it was much less bright in colour. Weight, 12 stones 4 pounds-a gain of four pounds. Oct. 21st. : The patient completed a course of arsacetin of which he had had 70 grains. All active symptoms had disappeared and his general health and appearance had improved much-in fact, his health was excellent.

CASE 20.--Private —- Irish Guards, was admitted on Sept. 23rd suffering from phimosis, cedema of the prepuce, and marked induration at the tip of the prepuce. There was a well-marked maculo-papular eruption on the chest, the abdomen, and the back. The lymphatic glands of the groin were somewhat enlarged, as also were those of the neck. The patient's weight was 10 stones 4 pounds. The patient was circumcised on Sept. 30th. The prepuce was found to be very hard and indurated, especially the lower part. Oct. 7 th : The patient had had three injections (21 grains). The rash was fading and the patient had gained three pounds in weight, which now was 10 stones 7 pounds. Oct. 14th: The rash had almost completely gone except for a few yellowish spots in the flank. The circumcision was healing up and the lymphatic glands were less indurated. Oct. 21st : 70 grains of arsacetin had been injected and all the above symptoms had gone. The patient's health and appearance were excellent and he was discharged to duty.

CASE 21. - Private —-, 1st Scots Guards, was admitted to hospital on Oct. 9th. There was no history of a primary sore and there was no sign of one but he had been in hospital in September last for balanitis. He now had a well-marked pigmented eruption on the lower part of the abdomen, the thighs, the buttocks, and the legs. The rash had probably been on the body for some time. The tonsils and the throat were congested and there was a tendency to mucous patches. Both the inguinal and cervical glands were indurated. Weight on admission, 11 stones 2 pounds. Oct. 14th : The patient had had three injections ( 21 grains). The rash was clearing off considerably except for a few pigmented spots on the thighs. Weight, 11 stones 4 pounds, a gain of two pounds. The throat was much better. Oct. 21st: Six injections of arsacetin had been administered (42 grains). The rash had gone, the throat had healed, and the general appearance was good.

\section{The Preparations Used.}

Soamin.-Of the preparations used soamin was employed in 26 of the above cases. As already described in the paper quoted above, soamin is a para-amino-phenyl-arsonate having the formula $\mathrm{C}_{6} \mathrm{H}_{4} \mathrm{NH}_{2} \mathrm{ASO}(\mathrm{OH})(\mathrm{ONa}) 5 \mathrm{H}_{2} \mathrm{O}$-in fact, it approximates very closely to the original preparation atoxyl. It has the advantage over the latter in that its purity can be assured. As will be seen, all these 26 cases had their full course of soamin which consists of a total of 100 grains and in only two were there the slightest bad effects (Cases 15 and 16); both as recorded showed slight toxic symptoms after they had had their eighth injection. The fact that the patients concerned were over 50 years of age might possibly account for the effects.

Arsacetin.-Eight of the series were treated with the arylarsonate known as "arsacetin" recommended by Ehrlich, as also by Professor Neisser ; it is a sodium acetyl-phenylarsonate. $\left(\mathrm{C}_{6} \mathrm{H}_{4} \mathrm{NHCH}_{3} \mathrm{CO}\right)$. AsOOHONa $=$ arsacetin. Professor Neisser says of it: " 1 . The preparation is certainly far less toxic than the old atoxyl, both healthy and diseased animals tolerating very much larger doses of arsacetin than of atoxyl. 2. As far as it is possible to make any com. parison as to the remedial action on syphilis he thinks there is no doubt but that everything favours arsacetin. 3 . No decomposition of any kind in the solution, even when stored for a long time, could be detected, nor does boiling daily alter the solutions in any respect." At Rochester Row in the above cases I have been giving 40 minims of a 15 per cent. solution every second day, this is equal to seven grains of arsacetin. The preparation can be employed in either a 10 per cent. or a 15 per cent. solution. The latter has the ad. vantage that it does not require the injection of so large a quantity of fluid and consequently the temporary painfulness in the locality of the injection is slighter; there is, however, this disadvantage that the 15 per cent. solution deposits the salt when cold, so that before use it is necessary to heat it to bring it into solution again.

Comparison of the salts. - It is hard to give a definite opinion, at present, as to which of these two arylarsonate preparations is the most efficient owing to one's limited experience as regards arsacetin; at the same time one cannot help being very much struck by the remarkable results one has seen following its use in the cases treated, and it certainly possesses undoubted advantages over soamin, in that its solutions do not decompose; hence it is unnecessary to make them up fresh daily as is the case with soamin.

Conclusion. - The good results obtained from the use of arylarsonates in this further series of cases go to strengthen one's conviction that in them we possess a second specific for syphilis, at least from a preventive and remedial point of view. As regards the former I have at present ten cases under observation which were originally admitted with what were in my judgment undoubted primary lesions of syphilis, and in seven of which the spirochrta pallida was demonstrated; these cases underwent courses of soamin, varying from between 60 and 100 grains, and have now been all closely observed every week during the last ten months without developing any further sign of syphilis. From the remedial point of view the good results of these 34 cases speak for it. But as a curative agent it is bezond us at present to give a positive answer to this all-important question; time and clinical experience alone will enable us to do so; nor can this be done until it is proved with. out doubt that arylarsonates are capable of permanently expelling the spirochæta pallida from the system, as indicated by the patient being rendered capable of reinfection. Neisser's successful experiments on apes from this point of view justify us in hoping for this end. Until the question as to the capability of arylarsonates bringing about a permanent cure is fully established (which it is hoped Wassermann's serum test will be able to tell us for certain), I consider that after a course of arylarsonates mercury should be given, and for this purpose, after my patients have com. pleted a course of arylarsonates, I put them on intramuscular injections of metallic mercury.

Military Hospital, Rochester-row.

Medical Sickness ANd Accident Society.--A meeting of this society was held on Nov. 20th, Dr. F. de Havilland Hall being in the chair. The list of sickness claims examined by the committee was a long one, and as is usual at this time of the year showed signs of rapidly growing. On the whole, however, the sickness business of the autumn has been favourable to the society and has worked off a good proportion of the loss that was sustained in the spring: The list of " chronics," that is, of permanently disabled members, continues to grow and more than $£ 4000$ a year are now being disbursed in respect of them. A large special reserve will be made for these at the approaching valuation of the society's business. Prospectuses and all further particulars can be had on application to Mr. F. Addiscott, secretary, Medical Sickness and Accident Society, 33, Chancery-lane, London, W.C. 